\title{
PERANAN PENYULUH TERHADAP PENGAMBILAN KEPUTUSAN PETERNAK DALAM ADOPSI INOVASI TEKNOLOGI PETERNAKAN DI KECAMATAN SANGKUB KABUPATEN BOLAANG MONGONDOW UTARA
}

\author{
Zulfikar Lamarang, B. F. J. Sondakh*, Anneke K. Rintjap, Adrie A. Sajow \\ Fakultas Peternakan Universitas Sam Ratulangi Manado, 95115
}

\begin{abstract}
ABSTRAK
Kegiatan Penyuluhan merupakan salah satu upaya pemerintah yang memiliki peranan penting dalam meningkatkan pengetahuan, keterampilan dan sikap untuk beternak. Penyuluh memiliki peran penting dalam pengembangan peternakan dan peningkatan proses adopsi teknologi peternakan kepada para peternak. Tujuan penelitian ini adalah mengkaji peranan penyuluh terhadap pengambilan keputusan peternak dalam adopsi inovasi teknologi peternakan di Kecamatan Sangkub Kabupaten Bolaang Mongondow Utara. penelitian ini dilakukan dengan metode survei, menggunakan responden yang dipilih dengan menggunakan metode purposive dengan memiih 3 desa dari 16 desa yang ada di Kecamatan Sangkub Kabupaten Bolaang Mongondow Utara dan memilih 30 responden dari kelompok peternak terpilih, yang dilakukan seara acak. Pengumpulan data dilakukan dengan wawancara, observasi dan dokumentasi.Sumber data yang diambil meliputi data primer berupa identitas responden, jumlah ternak yang dipelihara, teknologi yang diterapkan dan peran penyuluh.Data sekunder diperoleh dari instansi terkait dengan penelitian ini yaitu Dinas Pertanian Kabupaten Bolaang Mongondow Utara, Balai Penyuluhan Pertanian Perikanan Dan Kehutanan (BP3K) Kecamatan Sangkub dan Badan Pusat Statistik Kabupaten Bolaang Mongondow. Data dianalisis dengan menggunakan metode skoring dan analisis deskriptif. Hasil penelitian menunjukkan bahwa kecenderungan penilaian peternak terhadap
\end{abstract}

Korespondensi (corresponding author): Email: bfjsondakh@yahoo.com
Perananpenyuluhpertanian sebagai motivator, dinamisator dan fasilitator di Kecamatan Sangkub Kabupaten Bolaang Mongondow Utara sudah optimal. Hasil penelitian di lapangan menunjukkan bahwa proses adopsi peternak sapi di Kecamatan Sangkub adalah bervariasi mulai dari responden yang belum mengetahui tentang teknologi peternakan, sudah mencoba dan sudah menerapkan. Dan Peranan penyuluh memiliki pengaruh terhadap pengambilan keputusan peternak dalam adopsi inovasi teknologi peternakan di Kecamatan Sangkub Kabupaten Bolaang Mongondow Utara.

Kata kunci : Peranan Penyuluh, Proses Adopsi, Pengambilan Keputusan

\section{ABSTRACT}

THE ROLE OF EXTENSIONISTS TO THE DECISION OF FARMERS IN THE ADOPTION OF TECHNOLOGICAL INNOVATION FARMS IN SANGKUB SUB-DISTRICT, NORTH BOLAANG MONGONDOW DISTRICT.Extension activities is one of the goverment's efforts that have an important role in improving knowledge, skills and attitude to livestock. Extension workers have an important role in the development of livestock breeding and improvement of livestock technology adoption process to farmers. The purpose of this study was to examine the role of extension workers in decision making farmers in the adoption of technological innovation farms in District of Sangkub North of Bolaang Mongondow regency. This research was done by survey method. Three villages was selected using purposive method. Thirty respondents then selected from breeder groups, which is done randomly. Data collection was done by 
interview, observation and documentation. The sources of data taken include primary data in the form of respondent identity, the number of livestock kept, the technology applied and the role of extension workers. Secondary data obtained from agriculture office of north Bolaang Mongondow regency, agricultural and forestry extension agency (BP3K) of Sangkub sub-district and central bureau of statistics Bolaang Mongondow. Data were analyzed by using scoring method and descriptive analysis. Result of the research indicate that the tendency of farmer appraisal to agriculture extension role as motivator, dynamic and facilitator in district of Sangkub Regency of North Bolaang Mongondow was optimal The results showed that the process of adoption of cattle ranchers in Sangkub subdistrict North of Bolaang Mongondow regency is varied from respondents who do not know about farming technology, have tried and already apply. And the role of extensionists have and influence on the dicision of farmers in the adoption of farm technology innovation in Sangkub subdistrict.

Keywords : The role of extensionists, Adoption process, Decision - making

\section{PENDAHULUAN}

Kegiatan Penyuluhan merupakan salah satu upaya pemerintah yang memiliki peranan penting dalam meningkatkan pengetahuan, keterampilan dan sikap untuk beternak. Peranan penyuluh tidak hanya menyampaikan informasi kepada petaniternak tetapi juga harus mampu menambah, mengubah, dan membangun aspek-aspek pengetahuan (cognitive), sikap (affective), maupun keterampilan (psychomotoric) petani-ternak sehingga mereka mampu bertani dan berusaha lebih baik serta menguntungkan.

Penyuluh memiliki peran penting dalam pengembangan peternakan dan peningkatan proses adopsi teknologi peternakan kepada para peternak. . Keberhasilan proses dalam adopsi teknologi sangat ditentukan oleh model penyuluhan yang sesuai dengan kebutuhan peternak, yaitu ketepatan materi, metode dan media yang digunakan. Penyuluhan yang dilaksanakan dikatakan meningkat apabila terjadi perubahan pengetahuan, keterampilan dan sikap dari peternak dalam mengadopsi teknologi untuk meningkatkan cara beternak agar lebih baik.

Usaha peternakan yang dilakukan secara intensif sangat berkaitan erat dengan inovasi-inovasi dibidang peternakan antara lain, pemanfaatan limbah ternak menjadi biogas dan pemanfaatan jerami padi (limbah pertanian) melalui teknologi fermentasi sebagai pakan ternak. Namun terkadang peternak sulit menerima suatu perubahan atau hal yang baru, mereka merasa telah puas dengan apa yang mereka jalankan walau terkadang hasilnya kurang memuaskan.

Inovasi teknologi usaha peternakan yang telah diperkenalkan belum sepenuhnya diadopsi oleh seluruh kelompok peternak.Meskipun inovasi teknologi tersebut telah ada di tingkat peternak dan telah disosialisasikan kepada peternak, tetapi 
sejauh ini masih terdapat sikap masyarakat peternak yang menolak inovasi teknologi tersebut.

Mengingat fakta di lapangan masih terdapat kesenjangan antara teknologi yang dianjurkan penyuluh dengan teknologi yang dibutuhkan peternak, menimbulkan pertanyaaan apakah proses penyuluhan (dari penyuluh ke peternak) telah berlangsung dengan benar ?Tidak dapat dipungkiri bahwa untuk memanfaatkan teknologi baru, petani memerlukan modal yang lebih besar.Di samping itu mengubah kebiasaan bukan merupakan pekerjaan yang mudah, apalagi jika beresiko terlalu besar.

Berdasarkan hal yang telah dikemukakan maka dilakukan penelitian yang bertujuan untuk Mengkaji peranan penyuluh terhadap pengambilan keputusan peternak dalam adopsi inovasi teknologi peternakan di Kecamatan Sangkub, Kabupaten Bolaang Mongondow Utara.

\section{METODE PENELITIAN}

Penelitian ini dilaksanakan di Kecamatan Sangkub Kabupaten Bolaang Mongondow Utara.Metode pengumpulan data menggunakan metode survey.Pengambilan sampel dilakukan secara purposive dengan memilih 3 Desa dari 16 Desa yang ada di Kecamatan Sangkub Kabupaten Bolaang Mongondow Utara dengan kriteria peternak yang tergabung dalam kelompok ternak sapi dan sudah beternak minimal 1 tahun. Sedangkan penentuan kelompok peternak dilakukan secara acak.Sampel peternak dipilih 30 orang yang mewakili 3 kelompok peternak di Kecamatan Sangkub Kabupaten Bolaang Mongondow Utara.untuk mengetahui peranan penyuluh terhadap pengambilan keputusan peternak dalam adopsi inovasi teknologi peternakan maka dilakukan analisis deskriptif kualitatif (Nawawi 1995). Metode untuk mengambil skor yaitu mengacu dari teori likert.Semua kriteria penilaian peranan penyuluh pertanian diberi skor sesuai dengan yang telah ditentukan. Adapun perhitungan yang digunakan untuk menentukan interval penilaian terhadap peranan penyuluh yaitu jumlah skor tertinggi dikurangi skor terendah per banyaknya kategori.Maka hasil tersebut yang menjadi penentu interval (kategori baik / tidak baik) tiap indikator.

\section{HASIL DAN PEMBAHASAN}

\section{Karakteristik Responden}

Responden yang diambil dalam penelitian ini adalah peternak sapi yang masuk pada kelompok ternak masingmasing yang ada di desa Monompia, Tombolango dan Busisingo Kecamatan Sangkub. Jumlah responden dalam penelitian ini adalah 30 orang yang berasal dari 3 kelompok peternak .karakteristik peternak yang diteliti terdiri dari umur, 
tingkat pendidikan, jumlah pemilikan ternak dan pengalaman beternak.

\section{Umur}

Umur merupakan salah satu faktor yang dapat mempengaruhi produktivitas kerja seseorang. Tingkat umur seseorang akan berpengaruh terhadap kemampuan dalam mengerjakan pekerjaannya, karena terjadi peningkatan kemampuan fisik seiring dengan meningkatnya umur dan pada umur tertentu akan terjadi penurunan produktivitas.

Dari hasil penelitian menunjukkan bahwa kisaran umur petani cukup bervariasi yaitu antara 17 - 60 tahun.Pembagian golongan umur petani dibagi menjadi tiga interval umur yaitu umur $<41$ tahun, 41 -50 tahun, > 50 tahun. Kebanyakan petani responden berumur 41 - 50 tahun, yaitu sebanyak 12 orang $(40 \%)$ dan yang paling rendah yaitu umur $>50$ tahun sebanyak 8 orang $(26,67 \%)$, hal ini berarti rata - rata peternak di Kecamatan Sangkub, Kabupaten Bolaang Mongondow Utara, masih berada pada kelompok usia produktif untuk melakukan pekerjaan atau menjalankan usahanya.

\section{Tingkat Pendidikan}

Dari hasil penelitian menunjukkan bahwa sebagian besar peternak lulusan sekolah dasar (SD) sebanyak 11 orang (36,67 \%), lulusan SMP sebanyak 10 orang
$(33,33 \%)$, lulusan SMA sebanyak 8 orang $(26,67 \%)$ dan lulusan sarjana (S1) sebanyak 1 orang $(3,33 \%)$. Tingkat pendidikan peternak di desa Monompia, desa Tombolango dan desa Busisingo masih tergolong rendah. Rendahnya tingkat pendidikan peternak tersebut akan menyebabkan peternak kurang bijaksana dalam mengambil keputusan dan menjadi faktor penghambat kelancaran kegiatan adopsi pertanian, sehingga inovasi baru di bidang pertanian (dalam hal ini teknologi peternakan) cenderung lambat diterima dan perubahan lambat terjadi pada akhirnya akan menentukan keefisienan peternak dalam berusaha. Pendidikan berpengaruh pada cara berfikir peternak yang akan melaksanakan kegiatan usaha ternaknya. Peternak yang lebih lama mendapatkan pendidikan formalnya lebih besar kemungkinan akan lebih mudah menerima inovasi serta perubahan dalam hal beternak ayam broiler khususnya di lokasi penelitian. Seperti pendapat yang dikemukakan Soekartawi (1988) dalam Widya Lestari (2009), bahwa petani yang berpendidikan tinggi relative lebih cepat melaksanakan adopsi inovasi.

\section{Jumlah Kepemilikan Ternak}

Pada umumnya usaha ternak sapi di Kecamatan Sangkub merupakan peternak rakyat.Hal ini dibuktikan dengan hasil wawancara beberapa peternak tahun 2016 pada umumnya sebagian besar peternak 
memiliki populasi ternak berkisar 1-5 ekor.Menurut Siregar (2009) bahwa petani yang memiliki ternak 1-2 ekor sapi potong merupakan usaha ternak sapi potong yang bersifat tradisional.

Menurut Bessant (2005) bahwa skala kepemilikan sapi potong petani -peternak yang bersifat sebagai peternak rakyat dikelompokkan menjadi 3 bagian yaitu skala kecil (1 - 5 ekor), skala menengah (6 - 10 ekor) dan skala besar ( $>10$ ekor).

\section{Peranan Penyuluh Pertanian}

Penyuluh pertanian diharuskan membuat perencanaan tentang beberapa hal yang dapat membantu petani dalam mengemukakan pendapat, mengambil keputusan yang efektif serta dapat meningkatkan produktivitas kelompok peternak sapi yang ada di Kecamatan Sangkub Kabupaten Bolaang Mongondow Utara. Adapun variabel yang dapat dijadikan pengukuran peranan penyuluh pertanian di Kecamatan Sangkub Kabupaten Bolaang Mongondow Utara terhadap kelompok tani antara lain peran penyuluh pertanian sebagai Motivator, Dinamisator dan Fasilitator.

Adapun inovasi teknologi yang disuluhkan antara lain pemanfaatan jerami padi sebagai pakan ternak dan pemanfaatan limbah ternak menjadi biogas serta pupuk organik.

\section{Penyuluh Pertanian Sebagai Motivator}

Penyuluh pertanian senantiasa membuat peternak tahu, mau dan mampu menerapkan informasi inovasi yang dianjurkan. Penyuluhan sebagai proses pembelajaran (pendidikan nonformal) yang ditujukan untuk peternak dan keluarganya yang memiliki peran penting didalam pencapaian tujuan pembangunan bidang peternakan.

Indikator yang digunakan untuk menilai kemampuan peranan penyuluh peternakan sebagai motivator yaitu, peran penyuluh dalam menyampaikan informasi inovasi teknologi, peran penyuluh dalam memotivasi agar peternak mau menerapkan inovasi teknologi dan peran penyuluh dalam mengajarkan dan mempraktekkan inovasi teknologi agar peternak mampu menerapkan teknologi tersebut. Sedangkan kriteria yang digunakan adalah sebagai berikut : kriteria sangat baik yaitu peternak menilai bahwa penyuluh peternakan sangat mampu melaksanakan tugas-tugasnya sebagai motivator secara optimal, kriteria baik yaitu peternak menilai bahwa penyuluh peternakan mampu melaksanakan tugastugasnya sebagai motivator secara baik, kriteria cukup yaitu peternak melihat bahwa peran penyuluh sebagai motivator sudah cukup melaksanakannya secara optimal dan kriteria kurang baik yaitu peternak menilai bahwa peran penyuluh sebagai motivator kurang optimal dalam menjalankan tugas- 
tugasnya. Adapun kriteria penilaian peternak terhadap peranan penyuluh peternakan sebagai motivator dapat dilihat pada tabel 1 .

Pada tabel 1, dapat diketahui bahwa kategori sangat baik menjadi jawaban responden sejumlah 10 orang dengan persentasi $33.33 \%$, responden yang menjawab baik sejumlah 10 orang dengan persentasi $33.33 \%$, responden yang menjawab cukup baik sejumlah 1 orang dengan persentasi $3.34 \%$ dan responden yang menjawab kurang baik sejumlah 9 orang dengan persentasi $30.00 \%$. Ini menunjukkan bahwa sebagian besar responden yang menilai peran penyuluh pertanian sebagai motivator dalam melaksanakan tugas-tugasnya sudah optimal atau baik.

\section{Penyuluh Pertanian Sebagai Dinamisator}

Penilaian peranan penyuluh pertanian sebagai dinamisator adalah penilain peternak terhadap kemampuan penyuluh pertanian dalam menjalankan tugas-tugasnya untuk menggerakkan peternak melakukan perubahan dalam beternak yang lebih maju. Indikator yang digunakan untuk menilai kemampuan peranan penyuluhan pertanian sebagai dinamisator yaitu, peran penyuluh dalam merubah cara beternak petani menjadi lebih maju, peran penyuluh dalam menggerakkan peternak untuk merubah cara beternak yang masih tradisional menjadi lebih maju dan kemampuan penyuluh dalam menggerakkan peternak untuk menerapkan inovasi teknologi. Adapun kriteria penilaian peternak terhadap peranan penyuluh pertanian sebagai dinamisator dapat dilihat pada tabel 2.

Tabel 1. Penilaian Peternak Sapi Terhadap Peranan Penyuluh Pertanian Sebagai Motivator

\begin{tabular}{lccc}
\hline $\begin{array}{l}\text { Penilaian } \\
\text { Peternak }\end{array}$ & Skor & Jumlah Responden & \% \\
\hline Sangat Baik & $\geq 13$ & 10 & 33,33 \\
Baik & $10-12$ & 10 & 33,33 \\
Cukup Baik & $7-9$ & 1 & 3,34 \\
Kurang Baik & $4-6$ & 9 & 30,00 \\
\hline \multicolumn{1}{c}{ Jumlah } & - & $\mathbf{3 0}$ & $\mathbf{1 0 0}$ \\
\hline
\end{tabular}


Tabel 2. Penilaian Peternak Terhadap Peranan Penyuluh Pertanian Sebagai Dinamisator

\begin{tabular}{cccc}
\hline $\begin{array}{c}\text { Penilaian } \\
\text { Peternak }\end{array}$ & Skor & Jumlah Responden & \% \\
\hline Sangat Baik & $9,75-12,0$ & 9 & 30,00 \\
Baik & $7,6-9,74$ & 11 & 36,67 \\
Cukup Baik & $5,26-7,5$ & 0 & 0 \\
Kurang Baik & $3,0-5,25$ & 10 & 33,33 \\
\hline Jumlah & - & $\mathbf{3 0}$ & $\mathbf{1 0 0}$ \\
\hline
\end{tabular}

Dari tabel 2 dapat diketahui bahwa kategori sangat baik menjadi jawaban responden sejumlah 9 orang dengan persentasi $30.00 \%$, responden yang menjawab baik sejumlah 11 orang dengan persentasi $36.67 \%$, dan responden yang menjawab kurang baik sejumlah 10 orang dengan persentasi $33.33 \%$. Ini menunjukkan bahwa sebagian besar responden yang menilai peran penyuluh pertanian sebagai dinamisator dalam melaksanakan tugastugasnya sudah optimal atau baik.

\section{Penyuluh Pertanian Sebagai Fasilitator}

Penilaian penyuluh pertanian sebagai fasilitator adalah penilaian peternak terhadap penyuluh pertanian dalam menjalankan tugas-tugasnya sebagai perantara peternak dengan pihak-pihak yang mendukung perbaikan dan kemajuan usahanya.Indikator yang digunakan untuk menilai kemampuan peranan penyuluhan pertanian sebagai fasilitator yaitu, penyuluh pertanian sebagai pemberi arahan kepada peternak tentang sumber informasi inovasi teknologi, penyuluh pertanian sebagai pemberi kemudahan untuk menyelesaikan permasalahan peternak dan kemampuan penyuluh dalam mengfasilitasi peternak tentang sumber informasi inovasi.Adapun kriteria penilaian peternak terhadap peranan penyuluh pertanian sebagai fasilitator dapat dilihat pada tabel 3 .

Tabel 3. Penilaian Peternak Sapi Terhadap Peranan Penyuluh Pertanian Sebagai Fasilitator

\begin{tabular}{cccc}
\hline Penilaian Peternak & Skor & Jumlah Responden & \% \\
\hline Sangat Baik & $9,75-12,0$ & 9 & 30,00 \\
Baik & $7,6-9,74$ & 8 & 26,67 \\
Cukup Baik & $5,26-7,5$ & 3 & 10,00 \\
Kurang Baik & $3,0-5,25$ & 10 & 33,33 \\
\hline Jumlah & - & $\mathbf{3 0}$ & $\mathbf{1 0 0}$ \\
\hline
\end{tabular}


Tabel 4. Rekapitulasi Penilaian Peternak Terhadap Peranan Penyuluh Sebagai Motivator, Dinamisator Dan Fasilitator

\begin{tabular}{lccc}
\hline \multirow{2}{*}{ Penilaian Peternak } & \multicolumn{3}{c}{ Peran Penyuluh } \\
\cline { 2 - 4 } & Motivator & Dinamisator & Fasilitator \\
& $\boldsymbol{\%}$ & $\boldsymbol{\%}$ & $\boldsymbol{\%}$ \\
\hline Sangat Baik & 33,33 & 30,00 & 30,00 \\
Baik & 33,33 & 36,67 & 26,67 \\
Cukup Baik & 3,34 & 0 & 10,00 \\
Kurang Baik & 30,00 & 33,33 & 33,33 \\
\hline
\end{tabular}

Dari tabel 4dapat diketahui bahwa kecenderungan penilaian peternak terhadap peranan penyuluh pertanian sebagai motivator adalah sudah optimal atau peran penyuluh sebagai dinamisator telah menjalankan tugas-tugasnya dengan baik.Sedangkan penilaian peternak terhadap peranan penyuluh pertanian sebagai dinamisator adalah sudah baik atau sudah menjalankan tugas-tugasnya dengan baik.Dan penilaian peternak terhadap peranan penyuluh pertanian sebagai fasilitator dalam menjalankan tugastugasnya adalah sudah baik.

Rekapitulasi penilaian peternak terhadap peran penyuluh telah diketahui bahwa peran penyuluh sebagai motivator adalah sangat tinggi.Hal ini dikarenakan materi penyuluhan sesuai dengan kebutuhan peternak, menggunakan komunikasi yang sesuai atau mudah dipahami dan karena penyuluh melakukan kunjungan langsung di lokasi peternakan.

\section{Proses Adopsi}

Rogers dan Shoemaker (1971) menyatakan bahwa proses adopsi merupakan proses mental yang terjadi pada diri seseorang sejak pertama kali mengenal inovasi sampai memutuskan untuk mengadopsi inovasi tersebut. Menurut Samsudin dalam Tri Ratna Saridewi dan Amelia Nani Siregar (2010) proses adopsi teknologi merupakan proses perubahan perilaku melalui tahapan: mengetahui, memperhatikan, menilai, mencoba dan menerapkan. Samsudin (1987), Adapun tahapan proses adopsi inovasi peternak sapi di Kecamatan Sangkub Kabupaten Bolaang Mongondow Utara dapat dilihat pada tabel berikut. 
Tabel 5. Tahapan Proses Adopsi inovasi Peternak Sapi Di Kecamatan Sangkub Kabupaten Bolaang Mongondow Utara

\begin{tabular}{lcc}
\hline \multicolumn{1}{c}{ Tahap Adopsi } & Jumlah Responden & Persentase (\%) \\
\hline Belum Mengetahui & 10 & 33,33 \\
Sudah Mencoba & 10 & 33,33 \\
Sudah Menerapkan & 10 & 33,33 \\
\hline \multicolumn{1}{c}{ Jumlah } & 30 & 100
\end{tabular}

Dari tabel 5, dapat diketahui bahwa jumlah responden yang menjawab belum mengetahui inovasi teknologi peternakan sejumlah 10 orang dengan persentasi $33.33 \%$, responden yang sudah mencoba inovasi teknologi peternakan sejumlah 10 orang dengan persentasi $33.33 \%$ dan responden yang telah menerapkan teknologi peternakan sejumlah 10 orang dengan persentasi $33.33 \%$.

Hasil wawancara dengan responden bervariasi mulai dari yang belum mengerti teknologi peternakan disebabkan karena kurangnya intensitas penyuluhan, sedangkan yang sudah mencoba teknologi disebabkan karena adanya penyuluhan tentang teknologi peternakan oleh penyuluh dan responden yang telah menerapkan teknologi karena telah mengetahui akan pentingnya teknologi peternakan dan dapat memperoleh keuntungan.

\section{Pengambilan Keputusan}

Tahap keputusan berlangsung ketika perorangan atau (unit lain dalam pengambilan keputusan) terlibat dalam aktivitas yang mendorong kearah suatu pilihan untuk mengadopsi atau menolak inovasi. Indikator yang digunakan untuk menilai pengambilan keputusan yaitu siapa yang telah mengarahkan peternak dalam menerapkan teknologi peternakan, dan penyebab peternak belum menerapkan teknologi.Adapun sumber pengambilan keputusan peternak yang telah menerapkan teknologi peternakan di Kecamatan Sangkub Kabupaten Bolaang Mongondow dapat dilihat pada tabel 6 . 
Tabel 6. Sumber Pengambilan Keputusan Peternak Yang Telah Menerapkan Teknologi Peternakan Di Kecamatan Sangkub Kabupaten Bolaang Mongondow Utara

\begin{tabular}{ccc}
\hline Sumber Pengambilan Keputusan & Jumlah Responden & Persentase (\%) \\
\hline Penyuluh & 10 & 100 \\
Kelompok & - & - \\
Pemerintah & - & - \\
Petani Lain / Kerabat & - & - \\
\hline Jumlah & $\mathbf{1 0}$ & $\mathbf{1 0 0}$ \\
\hline
\end{tabular}

Dari tabel 6 dapat diketahui bahwa sumber pengambilan keputusan peternak yang telah menerapkan teknologi peternakan di Kecamatan Sangkub Kabupaten Bolaang Mongondow Utara adalah 100\% karena penyuluh.Dengan demikian penyuluh di Kecamatan Sangkub Kabupaten Bolaang Mongondow Utara sangat memiliki pengaruh terhadap pengambilan keputusan peternak yang telah menerapkan teknologi.

Adapun sumber pengambilan keputusan peternak yang telah mencoba inovasi teknologi di Kecamatan Sangkub Kabupaten Bolaang Mongondow Utara dapat dilihat pada tabel 7.padatabel 7 dapat diketahui bahwa sumber pengambilan keputusan peternak yang telah mencoba inovasi teknologi peternakan di Kecamatan Sangkub Kabupaten Bolaang Mongondow Utara adalah $100 \%$ karena penyuluh.Dengan demikian penyuluh di Kecamatan Sangkub Kabupaten Bolaang Mongondow Utara sangat memiliki pengaruh terhadap pengambilan keputusan peternak yang telah mencoba inovasi teknologi peternakan.Adapun alasan peternak yang belum menerapkan teknologi peternakan di Kecamatan sangkub Kabupaten Bolaang Mongondow Utara dapat dilihat pada tabel 8.

Tabel 7. Sumber Pengambilan Keputusan Peternak Yang Telah Mencoba Inovasi Teknologi Peternakan di Kecamatan Sangkub Kabupaten Bolaang Mongondow Utara

\begin{tabular}{ccc}
\hline Sumber Pengambilan Keputusan & Jumlah Responden & Persentase (\%) \\
\hline Penyuluh & 10 & 100 \\
Kelompok & - & - \\
Pemerintah & - & - \\
Petani Lain / Kerabat & - & $\mathbf{1 0 0}$ \\
\hline Jumlah & $\mathbf{1 0}$ & $\mathbf{1 0}$ \\
\hline
\end{tabular}


Tabel 8. Alasan Peternak Yang Belum Menerapkan Teknologi Peternakan di Kecamatan Sangkub Kabupaten Bolaang Mongondow Utara

\begin{tabular}{ccc}
\hline Alasan Belum Menerapkan & Jumlah Responden & Persentase (\%) \\
\hline Biaya Mahal & 2 & 20 \\
Belum Mengerti & 8 & 80 \\
Kurang Bermanfaat & - & - \\
Tidak Sesuai & - & - \\
\hline Jumlah & $\mathbf{1 0}$ & $\mathbf{1 0 0}$ \\
\hline
\end{tabular}

Dari tabel 8 dapat diketahui bahwa responden yang menjawab belum mengerti adalah sejumlah 8 orang dengan persentasi $80 \%$, sedangkan responden yang menjawab karena biaya mahal adalah sejumlah 2 orang dengan persentasi 20\%. Dengan demikian alasan kelompok peternak yang belum menerapkan teknologi peternakan di Kecamatan Sangkub Kabupaten Bolaang Mongondow Utara sebagian besar karena kurangnya pengetahuan tentang teknologi peternakan serta karena keterbatasan modal yang dimiliki peternak.Berdasarkan hasil wawancara dengan kelompok peternak sapi di Kecamatan Sangkub Kabupaten Bolaang Mongondow Utara, yang menjadi penyebab kurangnya pengetahuan peternak tentang teknologi peternakan disebabkan karena kurangnya intensitas penyuluhan.Oleh sebab itu peran penyuluh di Kecamatan Sangkub masih perlu ditingkatkan agar lebih mempermudah peternak dalam mendapatkan informasi tentang teknologi peternakan.

\section{KESIMPULAN}

Berdasarkan hasil dan pembahasan, maka dapat diambil 3 kesimpulan sebagai berikut :

1. Kecenderungan Penilaian peternak terhadap peranan penyuluh pertanian sebagai motivator, dinamisator dan fasilitator di Kecamatan Sangkub Kabupaten Bolaang Mongondow Utara yaitu sudah optimal atau peranan penyuluh dalam menjalankan tugastugasnya adalah sudah baik.

2. Hasil penelitian di lapangan menunjukkan bahwa proses adopsi peternak sapi di Kecamatan Sangkub adalah bervariasi mulai dari responden yang belum mengetahui tentang teknologi peternakan, sudah mencoba dan sudah menerapkan.

3. Peranan penyuluh memiliki pengaruh terhadap pengambilan keputusan peternak dalam adopsi inovasi teknologi 
peternakan di Kecamatan Sangkub

Kabupaten Bolaang Mongondow Utara.

\section{DAFTAR PUSTAKA}

Bessant, W. 2005.Analisis Usaha Peternakan Sapi Potong dalam Kaitannya dengan Kesejahteraan Peternak di Babupaten dan Kota Bogor.Prosiding Skripsi.Program Persetujuan Manajemen dan Bisnis, IPB.

Darmaludin, S. Suwasono . R.E. Muljawan. 2012. Peranan Penyuluh Pertanian Dalam Penguatan Usahatani Bawang Daun Di Kecamatan Sukapura Kabupaten Probolinggo. Buana Sains 12 (1): 71-80

Iskandar. 1999. Sumber Informasi Bagi Petani Dalam Penerapan Teknologi Usaha Kentang (Kasus di Kecamatan Pengalengan Dati II. Bandung). Tesis. Institut Pertanian Bogor : Bogor

Lestari W., S. Hadi dan N. Idris. 2009. Tingkat Adopsi Inovasi Peternak Dalam Beternak Ayam Broiler di
Kecamatan Bajubang Kabupaten Batang Hari. Jurnal Ilmiah Ilmu-ilmu Peternakan, 12.(1): 14-22

Mangare, G. 2016. Analisis Karakteristik Sosial Ekonomi Penyuluh Dengan Pelaksanaan Penyuluhan Di Kabupaten Minahasa.Jurnal Zootek (“Zootek" Journal ) 36 (2) : 333-341

Najib M dan H. Rahwita 2010. Peranan Penyuluh Pertanian Dalam Pengembangan Kelompok Tani Di Desa Bukit Raya Kecamatan Tenggarong Seberang Kabupaten Kutai Kartanegara. Fakultas Pertanian Universitas Mulawarman. 28 (2): 116-127

Nawawi. 1995. Dikata Evaluasi Penyuluhan Pertanian APP

Rogers, E M. and F. F Shoemaker. 1971. Communication Of Innovation. The Free Press: New York.

Saridewi T. R, dan A.N. Siregar. 2010. Hubungan Antara Peran Penyuluh Dan Adopsi Teknologi Oleh Petani Terhadap Peningkatan Produksi Padi Di Kabupaten Tasikmalaya. Jurnal Penyuluhan Pertanian 5(1): 55-61 